\title{
Managing Challenging Organizational Change: \\ Introducing Active Labor Market Policies in Italian Public Employment Agencies
}

\author{
Dr Alberto Asquer \\ Draft
}

\begin{abstract}
Managing organizational change in the public sector is extremely challenging when adverse conditions hamper the introduction of novel organizational practices. This study builds on the case of the implementation of active labor market policies in in Italy, in an attempt to help explaining the process of managing organizational change in the public sector. The case study shows how, despite contrary conditions that originate from the political context, the interplay between designed policy interventions, initial conditions, and features of the policy process can result in effective change of employment service practices.
\end{abstract}

Keywords

Organizational change, employment agencies, active labor market policies. 


\section{Managing Challenging Organizational Change: \\ Introducing Active Labor Market Policies in Italian Public Employment Agencies}

\section{INTRODUCTION}

Managing organizational change in the public sector is a challenging process when adverse context conditions hamper the introduction of novel organizational practices. Several studies have been done on how organizational change takes place in the public sector (Bryson and Anderson 2000; Kelman 2005; Thomas 1993; Wise 2002). These works highlighted that various factors contribute to the effectiveness of organizational change process, including employees' willingness to implement change and external support from political overseers and key external stakeholders (Fernandez and Rainey 2006; Tummers 2011). Adverse context conditions, such as sources of employees' alienation and of policy uncertainty, may hinder the effective reconfiguration of activities carried our by public organizations. Researching how organizational change in the public sector can effectively take place despite adverse conditions, then, is a type of inquiry that is worth undertaking in order to improve our understanding of how organizational change can be successfully managed.

During the last decades, the implementation of 'Active Labor Market Policies' (ALMPs) provides an instance of a context scenario that posed, in some countries at least, a demanding reconfiguration of activities performed by public employment agencies. Traditionally, public employment agencies (once typically branches of a central government department, such as the Ministry of Labor) were required to recognize unemployment status, disburse subsidies, and inspect compliance with employment rules. Currently, public employment agencies are also often required to implement programs intended to increase the likelihood that the unemployed may find a job, including actions to improve job-related skills, to facilitate access to the labor market, and to assist the functioning of the labor market in general (Calmfors 1994; Layard et al. 1991; Martin 2000). The implementation of ALMPs entails that public employment agencies need to develop the capacity to deliver new services to the unemployed, including consulting, training, job searching and matching, and collaborating with other entities, such as vocational education and training centers, charities, and headhunters (Lundin and Skedinger 2000), despite having no relevant experience.

The implementation of ALMPs has been conducted in different ways across countries. 
In Italy, a reform of the labor market passed in 2001 (Legislative Decree 180/2001) enlarged the statutory tasks of public employment agencies from 'traditional' bureaucratic assignments to the provision of ALMP-related services and devolved labor market policies from the central government to sub-national (regional and provincial) ones. These features of the policy reform design, together with circumstances related to the financial management of ALMPs, resulted in particular adverse conditions that could hamper the introduction of novel organizational practices. In spite of this, managerial efforts eventually succeeded in establishing new public employment agencies in place of former local branches of the Ministry of Labor and in ensuring that they develop novel organizational capabilities for delivering ALMP services.

The central aim of this paper is to assist in developing a theoretical account of the kind of organizational change in the public sector that takes place when public agencies' statutory tasks are significantly enlarged and public policy functions are devolved from the central to the sub-national level. This aim is pursued through a case study of the episode of organizational change that took place in a few public employment agencies in Sardinia, Italy, in the period 2001-2011. As we shall see, during this period new employees of the public employment agencies defined the features of ALMP services, designed procedures and standards of service delivery, and developed novel organizational routines for the provision of ALMP services to the unemployed. The case study will provide an explanation for how they were able to attain such accomplishments, despite the lack of any past experience of ALMPs, the lack of support from the regional government, and the presence of sources of uncertainty about their own job stability and career prospects. On the basis of the case study, then, we shall draw some qualifications of existing theoretical arguments about the role of employees' willingness to implement change and of external support from political overseers in the effective implementation of organizational change in the public sector.

This paper is organized as follows. Next section will provide the theoretical background that justifies the central research question and an account of data collection and analysis. The third section will narrate the episode of organizational change in public employment agencies in Sardinia in the period 2001-2011. Section four will offer an explanation for the trajectory of the process of organizational change in the selected public employment agencies. The last section will discuss the research findings in relation to existing theoretical arguments about the management of organizational change in the public 
sector.

\section{ORGANIZATIONAL CHANGE IN THE PUBLIC SECTOR}

Organizational change is an area of study that has attracted a considerable amount of interest, as witnessed by the copious volume of scholarly works so far. While most of these studies addressed issues related to organizational change processes in general (Armenakis and Bedeian 1999; Dawson 1994; Pettigrew et al. 2001), a specialized body of literature focused on organizational change in the public sector in particular. Research on organizational change in the public sector (Brown et al. 2003; Bryson and Anderson 2000; Coram and Burnes 2001; Fernandez and Rainey 2006; Kelman 2005; Thomas 1993; Wise 2002) has resulted in the formulation of theoretical arguments about how the organizational change process unfolds and what accounts for the success or failure of efforts to achieve it. Most of these studies highlighted that, contrary to a traditional view that related organizational change to a deliberate orchestrated effort (Lewin 1951), the process of changing organizational structures and practices is largely unplanned and unexpected (Kickert 2010; Weick 2000). Much scholarly attention, then, has been directed to better understanding the role of the implementers and of (possibly changing) context conditions on how organizational change unfolds.

The pivotal role of implementers in organizational change processes (as well as in public policy implementation more generally) has been long acknowledged (Lipsky 1980; Wallace et al. 2011). Some studies highlighted that a crucial condition for success of organizational change is that employees are willing to implement the change (Higgs \& Rowland 2005; Judson 1991). Employees' willingness to implement a policy mandate (that could include effecting change in organizational structure and practices) has been related to their perceived autonomy and to the meaningfulness of the policy for their own clients or for society at large (Tummers 2011). The stewardship theory (Davis et al. 1997; Donaldson and Davis 1989, 1991) also suggested that organizational actors are naturally inclined to implement actions that are believed to serve the interests of their clients and stakeholders. In relation to this, implementers are often able to overcome obstacles encountered in organizational change processes, including those that originate from a highly charged political environment (Harrow 2001).

Various studies also showed that features of the context play an important role in the 
organizational change processes (Devos et al. 2007; Greenwood and Hinings 1996; Pettigrew et al. 2001). The work of Fernandez and Rainey (2006), among others, included context conditions (in the form of external support from political overseers and key external stakeholders) among the eight key factors that account for the effectiveness of organizational change processes (other factors being: ensuring the need for change, providing a strategic plan for change, building internal support for change, ensuring top-management support and commitment, providing resources, institutionalizing change, and pursuing comprehensive change). The importance of context conditions that relate to the political environment was also emphasized by May and Winter (2007), who showed that both politicians and managers influence the behavior of street-level bureaucrats by means of signals that affect employees' perceptions of policy goals and their knowledge.

Several studies have also been done on organizational change in public employment agencies, in particular. The transition from the execution of 'traditional' bureaucratic assignments to the provision of ALMP-related services has been conducted in virtually all OECD countries, albeit it exhibited different local institutional and organizational features (Clasen and Clegg 2003; Davister et al. 2004). Various studies showed that the introduction of ALMPs in public employment agencies typically resulted in more flexibility and discretion to design and implement welfare programs, although it had relatively modest effect in making staff internalize the values of moving clients to self-sufficiency (Beckerman and Fontana, 2001; Lurie and Riccucci, 2003; Meyers et al., 1998; Riccucci et al., 2004; Thaden and Robinson 2010). It seems, then, that public employment agencies may well adopt new organizational structure and practices, but they may be relatively resistant to embracing any deeper level of culture change (Lurie and Riccucci 2003).

This paper aims to contribute to the inquiry into the process of managing organizational change in the public sector by addressing the question of how organizational change unfolded in a few public employment agencies (called Centri Servizi per il Lavoro or CSL) located in Sardinia, Italy (in local governments of Cagliari, Quartu Sant'Elena, Assemini, and Senorbì, that are included in the province of Cagliari). The case has been selected because of its particular process and context features that bear some relevance for theorizing what affects the organizational change process in the public sector (Eisenhardt and Graebner 2007). The case took place within a context that included adverse conditions that originated from the political environment, in the form of disputes over the devolution of labor 
market policies from the central government to sub-national government, of sources of uncertainty about the funding of job contracts for the staff performing ALMP-related services, and of tensions that arose from the issue image of the provinces as an unnecessary intermediate governance layer that lacked providing efficient and cost-effective services (within Italy's multi-layered system of governance, the provinces occupied a middle position between the regions and the municipalities, see Table 1). Also taking into account that initial conditions included a relatively high level of bureaucratization of 'traditional' unemployment services (at least, in comparison with other OECD countries), the outcome of the case episode - namely, one where the newly established public employment agencies were able to perform ALMP services and attain some limited accomplishments to help job-seekers to work counts as a partial success. In this sense, the case of organizational change of public employment agencies in Sardinia permits us to explore how organizational change can be effectively managed within a context of 'limit conditions' that would be generally associated with crucial obstacles to the implementation of a policy mandate.

$<$ insert Table 1 about here $>$

Data were collected through 21 interviews conducted in the period March-April 2011. Interviewees included the councilor responsible for labor policies in the provincial government of Cagliari, the general manager of the provincial department of labor, three managers of the CSL of Cagliari, Quartu Sant'Elena, and Senorbì, eight members of permanent staff and eight temporary staff (equally representing each of four CSL), for a total of about 12 hours. Interviewees differed in the periods of time when they participated in the episode under consideration, e.g., three managers of the CSL and permanent staff had been employed in the agencies since before 2001, while half of interviewed temporary staff had been hired in 2005 and the other half in 2007. Interviewees were questioned to tell the story of their experience with the implementation of ALMPs in the agencies (e.g, questions included: How were ALMP services introduced and launched? How was your work organized? How was the relationship with the permanent employees/with the new staff? What role did the regional/the provincial government play in the establishment of the CSL?). Interviewees were selected according to seniority criteria and reputation for job commitment and dedication. These selection criteria could have prevented detecting alternative narratives 
but the one that is presumably shared by managers and most diligent employees. This source of bias should be taken into account before drawing any inference about whether organizational actors attributed the same meaning to the organizational change episode and outcome. Indeed, the same 21 interviewees held partially conflicting views on such matters as, for example, perceived identity and role of different groups of employees (i.e., permanent and temporary staff). Bearing this caveat in mind, however, collected data contained a relatively rich corpus and, following the 'saturation method' (Gaskell and Bauer 2000), no additional interviewees were approached when the latest interviews did not seem to significantly enrich the variety and depth of evidence.

Collected data were categorized on the basis of a coding frame that evolved during the research process. Originally, the coding frame was based on theoretically derived concepts and constructs that originated from the scholarly literature on organizational change. Upon examination of the empirical evidence, the coding frame was progressively amended and enriched in order to reflect the various features of the discourse on the changes that had taken place in the public employment agencies under consideration (it eventually included primary codes, e.g., entities, actors, events, attitudes of actors towards organizational change processes, and several secondary codes). The evolution of the coding frame broadly followed the 'grounded theory' approach (Tummers and Karsten 2012) to data collection, which highlights the importance of understanding the cognitive structures of the empirical social domain under study. Coded data, then, were used for writing the narrative text of the episode of organizational change in the public employment agencies constructed around a framework of events (understood as abstract entities that are intellectually devised for making sense of history) rather than to the hierarchical structure of coding frame.

The analysis of data followed a processual theoretical framework for explaining the organizational changes process that took place in the four CSL. The importance of a processual approach to the study of social and organizational phenomena has been long highlighted by scholars in various fields, including political science (George and Bennett 2005) and organizational sociology (Pettigrew 1997). The processual method develops explanations that are especially attentive to time, path dependency, and changing context conditions (Mahoney 2000; Pierson 2000, 2004; Barzelay and Gallego 2006). A distinguishing feature of this approach is the use of social mechanisms (Hedström and Swedberg 1998; McAdam et al. 2001; Hedström 2005) as theoretical resources for explaining 
instances of the social or organizational process under consideration. Variously conceived as interpretations (Schelling 1998) or hypothetical causal models (Gambetta 1998) or plausible hypotheses that could be the explanation of some social phenomenon (Hedström and Swedberg 1998), social mechanisms provide (either in isolation or in concatenations; Gambetta 1998) hypothesized social interactions that are believed to cause the observable effects that are cast in the role of explananda. Within the present case study, social mechanisms have been employed to provide a plausible hypothesis of how initial conditions, process design features, and context conditions relate to the observed features of the path and outcome of the organizational change episode.

\section{ORGANIZATIONAL CHANGE IN PUBLIC EMPLOYMENT AGENCIES IN ITALY} (2001-2011)

\section{The implementation of the 2001 labor market reform}

In 2001, the central government of Italy passed a reform (Legislative Decree 180/2001) that devolved competences on labor market policies from the central to the sub-national level and redefined the statutory tasks of public employment agencies in the country. Until that time, labor market policies had been mainly carried out by local branches of the Ministry of Labor, named Sezioni Circoscrizionali per l'Impiego e il Collocamento in Agricoltura or SCICA. SCICA generally performed bureaucratic tasks related to the recognition of unemployment status, the disbursement of subsidies to beneficiaries, and the inspection of compliance with employment contracts and workplace rules, that were carried out in strict adherence to ministerial protocols. Following EU-level policy orientations (EU Commission 1998), the 2001 reform was part of a broader policy framework that included the opening up of the provision of employment services to business companies, the formulation of common strategic guidelines for the adoption of ALMPs at the sub-national level (the so-called 'Masterplan for employment services'), and the use of part of the 2000-2006 European Social Fund (ESF) for financing the implementation of ALMPs at the local level.

The implementation of the 2001 reform proceeded with different intensity and pace at the sub-national level across the country. In Sardinia, in 2002 a report commissioned by the regional government (Butera \& Partners 2002) proposed to establish new public employment agencies that would provide both the 'traditional' tasks performed by the local branches of the Ministry of Labor and the new ALMP services. These comprised (as defined by OECD 
guidelines; Martin 2000) public employment service and administration, labor market training, youth measures, subsidized employment, and measures for the disabled. Provincial governments would appoint the managers of the new public employment agencies and provide policy guidelines, while the regional government would formulate regional-level ALMPs and supervise their implementation, especially through the regional labor agency (Agenzia per il Lavoro) that had been established in 1988.

The 2002 report largely inspired the content of subsequent regional legislations (Regional Laws 9/2003 and 20/2005). The regional government mandated the establishment of 28 new public employment agencies (CSL), the creation of 55 special centers for socially and physically disadvantaged people (Centri Servizi per l'Inserimento Lavorativo or CeSIL), and the setting up of a new labor market information system (Sistema Informativo del Lavoro or SIL Sardegna). The 28 CSL were initially staffed with former SCICA employees (totaling about 180 individuals), who were asked to opt either to move to the CSL or to be transferred to the regional branch office of the Ministry of Labor, where they would be assigned to inspection activities only. As the 2002 report had shown that SCICA staff did not generally possess adequate skills for providing ALMP services (they generally held high school diplomas and had not been subjected to any training for acquiring additional competences in the past), the CSL were also staffed with about 270 temporary employees (short-term contract staff) mainly selected from young social science graduates (about $70 \%$ of the new hires held a degree). Temporary employees generally lacked any robust experience with ALMPs, although some of them had taken postgraduate studies on welfare policies. Since temporary employees were funded by the 2000-2006 ESF program on an ad hoc basis, the retention of the short-term contract staff became subject to the availability of alternative financial resources in the future.

\section{The establishment of new public employment agencies}

The establishment of the CSL took place within a rather unfavorable context. While the reform provided the devolution of various competences on labor market policies to the provincial level, the regional government undertook some initiatives that were not coordinated - or even conflicted - with those of the CSL. For example, it provided on-the-job training courses, internships, and scholarship funding that were planned and delivered without consulting or informing the managers of the CSL. In a bill proposal circulated in 
2010, the regional councilor of the Department of Labor envisaged the centralization of all ALMP services into new employment centers (called cittadelle del lavoro or 'labor towns') across the region in the form of branches of the regional labor agency. These initiatives persuaded the provinces that the regional government intended to reverse the decentralization of labor market policies that had been adopted by the central government since the late 1990s, and that the regional government had only halfheartedly accepted.

The policy orientation of the regional government made the provinces worried about the 'hollowing out' of their competences on ALMPs. Particular historical circumstances added further reasons for apprehension, because in the public sphere (at both the national and local level) the policy discourse frequently addressed the option to abolish the provinces, on the ground that these public authorities failed to provide efficient and cost-effective services. The provincial governments unanimously challenged this view by holding that the provincial administrations could better monitor, understand, and fulfill the expectations of the citizens than the regions could do, especially because of the proximity of decentralized provincial agencies to the most remote communities. In Sardinia, however, public acrimony against the provinces was also fueled by the widespread resentment for extra public spending after the establishment of four additional provinces in 2005 that had resulted from the de-merger of the four provinces that had traditionally operated in the region. Within this context, the provinces took seriously the possibility that they could be ultimately 'expropriated' of competences on labor market policies and, relatedly, that CSL could be closed down. The relationship between the regional and the provincial levels of government was described by the provincial councilor of the Department of Labor of Cagliari in this tone:

"The decentralization process has been stopped in its tracks. The region claims back prerogatives and does not leave any room for autonomy of provinces. (...) The 2000 Masterplan has been largely ignored by the regional government, despite recommendations made by the Ministry [of Labor] and in spite of the fact that other regions have already implemented it. (...) More generally, there is not a comprehensive regional policy for labor. For example, the region recently passed a new regulation of apprenticeship, but the provinces have not been invited to the negotiation table. The provinces have to search for information about apprenticeship opportunities because the region does not pass any details.” (Interview in Cagliari, March 2011) 
Notwithstanding these features of the context, both the provincial councilor of the Department of Labor and the managers of the CSL embarked on the establishment of the CSL with vigor. Rising unemployment rates during the 2000's made the implementation of the labor market reform a sensible political issue in various municipalities, including those of Cagliari, Quartu Sant'Elena, Assemini, and Senorbì (where more than 95,000 people were registered in unemployment lists, over about 485,000 residents in 2002 , i.e., almost $20 \%$ of the population; Pruna, 2011). After CSL were established, their managers promptly organized the human and physical resources needed to perform their statutory tasks. Physical resources especially included the CSL premises, which were refurbished in order to allocate more office space to face-to-face interactions (that better suited the delivery of most ALMP services). Human resources consisted of permanent employees (i.e., former SCICA staff and, in part, provincial administration personnel) and the temporary staff, who joined the CSL in two successive enrollment rounds in 2005 and 2007. Permanent employees were assigned to the 'traditional' administrative routines that had been carried out in the SCICA in the past, while the temporary staff was primarily assigned to ALMP services (reception, orientation, training, and measures for the disabled, that were launched in 2005, and assistance to business start-ups, counseling and job placement, that took off in 2007).

The delivery of ALMP services was exclusively dependent on the temporary staff - a policy community of individuals that shared a similar educational background and job network. At the core of ALMP services was the reception, which allowed to establish contact with new clients and to direct them to the appropriate ALMP program. New clients were generally required to take part to an induction program (so-called patto di servizio or 'service agreement') that included a briefing intended to identify the service program that better suited the client's needs, a short training course, and assistance for CV drafting. Special programs were provided for the assistance of socially and physically disadvantaged people and for the unemployed who aimed to start-up their own business. Additionally, clients could be provided with job placement services (so-called incontro domanda e offerta or 'demandsupply matching') that included the search for training courses, internships positions, and job offers, typically in collaboration with local authorities and firms.

\section{The design of new organizational arrangements}


The managers of the CSL played a major role in the design of novel organizational routines. After the temporary staff was hired, CSL managers organized a job rotation system that made the short-term contract employees participate in administrative service routines together with the permanent personnel. The assignment of temporary staff to administrative tasks made them acquainted with the nature of the work in the employment agencies and with the traits of the clients, and socialized them with the rest of the organization. In part, the job rotation system also helped CSL managers to increase service capacity of the agencies, especially when the permanent employees faced peak demand. Some of the temporary staff, however, resented the job rotation system as unsuitable for their role, especially with respect to the requirement to comply with a precise work schedule that they considered at odds with their presumed 'consulting' role. After some legal controversies, the temporary staff accepted to renew the job contracts by including terms on working conditions that required tracking working hours rather than providing consulting services on a client case basis.

In part, the design of novel organizational routines also relied on initiatives undertaken by the staff itself, rather than promoted by the CSL managers. Temporary employees engaged in frequent exchange of communications, especially for sharing ideas on the design of procedures for the provision of ALMP services, for which no established standards and routines yet existed. Also permanent employees frequently exchanged informal communications as a way of sharing their knowledge and opinions on such matters as interpretation of the legislation, policy directives, and client issues. These collaborative efforts were especially triggered by the sense of lack of direction and supervision that the former SCICA personnel resented in the CSL with respect to their former work practices. Before the implementation of the 2001 reform, the regional manager of the Ministry of Labor used to provide a consistent line of instructions to SCICA personnel for carrying out the assigned tasks. In contrast, the CSL generally operated without any close guidance and control by either the provincial councilor of the Department of Labor or the director of the provincial labor department. As one former SCICA employee put it:

"In the past, our work was guided by ministerial directives that clarified what should be done. The general manager of the regional branch of the Ministry of Labor provided a uniform interpretation of the directives, and a sense of coherence and unity. We worked smoothly; the over-bureaucratization of activities done under the Ministry of Labor is 
just an exaggerated myth. Nowadays, instead, we are uncertain as to how directives should be executed. And we are not helped by the provincial manager because there is too much turnover - while we had the same general manager of the Ministry for twenty years, we had five different people acting as general manager of the provincial department of labor in two years." (Interview in Assemini, March 2011)

The managers of CSL tried to provide some guidelines for making the agencies operate in a consistent way. They held regular monthly meetings (also with representatives of the labor departments of the region and of the province) for discussing common issues especially related to human resource management, IT upgrade, work standard procedures, and budgeting. Sharing the experiences carried out in different CSL triggered the imitation of organizational policies and procedures across the agencies. Work practices, accordingly, largely developed through progressive adjustments stimulated by exchange of ideas and experiences, rather than through the systematic review and assessment of organizational performance and corrective feedback. In effect, the CSL were managed with the support of a limited performance management system, that mostly provided information about staff workload and number of client cases, for reasons that included the lack of any policy directives and objectives from the side of the provincial government (an individual performance review and assessment system was in place, but it was considered by CSL managers ineffective to induce any motivational and learning effects).

Despite the efforts of the CSL managers, the permanent employees and the temporary staff did not develop any mutually collaborative attitude between each other. The relationship between the two groups was prejudiced by a sense of mistrust, 'us vs. them', centered on conflicting positions in the workplace. Permanent staff tended to diminish the role of ALMP services, which were perceived to roughly correspond to activities that SCICA already carried out in the past, or that were considered ineffective with respect to the needs of the clients. For example, a former SCICA employee argued:

"It is not clear to me what is 'new' in the expertise of the new staff. Before they arrived, we already did some of the stuff that is now called active labor market services, albeit in an improvised way. Unfortunately, there was no recognition of the expertise that we [former SCICA employees] formed in the field. I regret that I stayed to work in the 
province, although here I enjoy direct contact with clients." (Interview in Cagliari, March 2011)

This attitude could be related, in part, to the lack of a deep understanding of ALMPs from the side of the former SCICA personnel (as the Butera \& Partners' 2002 report had documented). This attitude, however, also seemed to originate from permanent employees' perception that the temporary staff posed a threat to their career prospects because of possessing higher qualifications. Temporary staff, instead, generally tended to distance themselves from any deep involvement in CSL activities beyond their contract obligations, especially because of the uncertainty of their job prospects that originated from the short-term basis of employment (generally contracts lasted for six months and were funded by renewed EU sources rather than from the personnel budget of the regional government). This quote from a temporary worker seems relevant here:

"I consider myself as a consultant, and therefore I expect to be allowed to work flexible hours and to be assessed on the basis of the results. Here, instead, it seems that we are just expected to be present in the workplace for a certain amount of time. What kind of objectives can we expect, anyway, if I am only provided a short-term horizon? Our contracts expire every six months." (Interview in Cagliari, March 2011)

\section{The development of work practices for delivering ALMP services}

Only gradually did ALMP services gain attention and appreciation among the clients. Originally, clients kept requiring mostly 'traditional' services, while they retained a rather skeptical attitude towards ALMP services. Generally, the unemployed were not willing to join the 'service agreement' (they generally dropped out of the induction program after a few meetings). Some clients resisted making commitments to attend orientation and training courses, especially when - despite the unemployment status - they were reported to carry out temporary jobs that were not registered. Other clients discounted the relevance of ALMP services, such as drafting the so-called 'skills balance sheet' (bilancio delle competenze), for improving their job prospects. Over time, however, early success cases and word-of-mouth resulted in recommendations for ALMP services, and an increased number of clients approached the CSL. 
On some occasions, the CSL seemed successful in stimulating their clients to adopt an 'entrepreneurial' approach to job search, to improve their job-related skills, and to establish collaborative relationships with other unemployed people in order to circulate information and tips about job opportunities. On the whole, however, the performance of ALMP services generally remained relatively unsatisfactory. Very few among the clients that approached the business start-ups counseling, for example, were able to implement their business ideas because of faulty business models, inadequate personal traits, or adverse business conditions. Several clients (and the same CSL staff) resented the limitations of the web-based labor information system, which had been designed and implemented without consulting providers and clients of ALMP services. Temporary staff was not fully informed of initiatives carried out by the regional Department of Labor and the regional labor agency, including on-the-job training courses, internships, and scholarship funding, which were often designed without any consultation with the CSL for identifying the needs of the unemployed.

While the number of clients of ALMP services increased, the temporary staff progressively codified the work practices into standard protocols and tools. As 'new entrants' in an area of labor market services that had never been provided until that time, they were free to design organizational routines and develop work practices from scratch, only subjected to the practical limitations posed by the IT system and the resources available. While they originally tended to self-manage client cases in a flexible consulting style, eventually (especially after the change of terms of working conditions) they came to deal with clients in a rather routinized approach. Having agreed with the tracking of working hours, the temporary staff also became essential for the delivery of 'traditional' services, especially in some CSL that would be unable to guarantee daily opening hours because some permanent employees were approaching retirement age (e.g., the CSL located in Muravera, that employed only five permanent employees).

The temporary staff, however, remained rather uncommitted to the activities of the CSL. As the continuation of funding for their employment in the CSL was uncertain, temporary employees often carried out occasional jobs outside the stipulated working hours. Lacking any long-term employment perspective, they generally refrained from investing extra time and efforts in perfecting organizational routines. The CSL managers, together with the provincial councilor of the Department of Labor, persistently called on the regional government to provide stable financial resources for funding their jobs. The temporary staff, 
however, remained based on short-term contracts during the whole period.

\section{DISCUSSION}

This section aims to explain how the process of organizational change in the CSL of Cagliari, Quartu Sant'Elena, Assemini, and Senorbì unfolded. The main issue at stake is how the CSL developed the work practices for delivering ALMP services, provided that (a) initial conditions included the lack of any expertise and routines for the provision of ALMP services and (b) context conditions included the conflictual relationship between the region and the provincial governments and sources of uncertainty about temporary employees' job prospects. Given such conditions, the development of work practices for the provision of ALMP services amounts to a non-trivial outcome of the implementation of the labor market reform in the case under consideration. As we shall see, the case study provides some evidence for qualifying existing theories about the causal role played by the institutional and temporal context (including, especially, the influence of political support from external stakeholders) and by employees' inclination to pursue the interest of their clients and stakeholders on organizational change process in the public sector.

In order to explain how work practices for delivering ALMP services developed, we first recall some characteristics of initial conditions, policy design and process features, and context conditions. Initial conditions that seem analytically relevant include features of permanent employees, especially their relatively low qualifications and capabilities mostly geared to performing bureaucratic tasks. Relevant policy design features include the enlargement of statutory tasks of the public employment agencies, especially the mandate to deliver ALMP services for which no expertise and practices had ever been accumulated in the past. Relevant policy process features include the employment of the temporary staff by means of short-term contracts and a 'silos' organizational design of the CSL that kept the 'traditional' administrative routines separated from the ALMP services. Context conditions, finally, especially include the conflictual relationship between the regional government and the provincial governments over the allocation of competences on labor market policies.

In explaining how these conditions resulted in the development of the work practices for delivering ALMP services, first we consider the role played by a combination of mechanisms of organizational learning, protection of identities and roles, and polarization. The scholarly literature on organizational learning highlighted that the development of 
organizational routines is typically associated with performance feedback cycles that stimulate behavioral change (Levitt and March 1988; Argyris and Schön 1996). The case evidence shows that the managers of the public employment agencies regularly met to review the conduct of the CSL and exchange ideas about issues encountered and possible solutions, albeit with the support of a limited performance management system. Managers' commitment to hold regular meetings provided stability to this performance review activity, that resulted in the sustained efforts of the managers of the CSL to align work practices within each CSL and between them. The stimuli provided by CSL managers, however, cannot fully account for the efforts exerted by temporary staff to develop the work practices to deliver ALMP services. An additional mechanism that seems analytically relevant, in this respect, is the protection of identities and roles (Wenger 2007), that relates to temporary staff's inclination to establish their presence and contribution to the activities done in the CSL in face of apparent hostile circumstances, that included the 'liability of newness' (Singh et al. 1986) charged on ALMP services and the 'newcomer status' of the temporary staff.

The case evidence also shows that the development of novel work practices took place within a climate of mistrust between permanent employees and temporary staff. A mechanism of polarization (McAdam et al. 2001), that refers to the progressive alienation between groups or factions, helps account for the formation of a contrasting frame ('us vs. them') between the two groups of employees related to features of initial conditions (relatively low qualifications of the former SCICA personnel and their perceptions of ALMP services), of the policy process (higher qualifications of the temporary staff), and of the policy design content (enlargement of statutory tasks of the public employment agencies). Some scholarly works highlighted that the lack of a supportive organizational climate might have detrimental effects on the development of organizational capabilities (Mahler 1997; Fiol and Lyles 1985). A question arises, then, concerning why - despite such unhealthy work relationship - the CSL were able to develop work practices for the provision of ALMP services anyway. In this respect, features of the policy process, in the form of the 'silos' organizational design, contributed to minimizing the interaction between work practices of the former SCICA personnel and of temporary employees. Such an organizational arrangement may have contributed to insulating the temporary staff from conflicts with the permanent employees, while it could allow them the room needed to establish their professional identities and roles by designing and implementing standard protocols and tools 
for the provision of ALMP services.

Although the temporary staff succeeded in developing novel work practices, the performance of ALMP services remained relatively modest. While the number of clients increased over time, ALMP services generally missed providing a consistent score of substantive achievements - in terms, for instance, of job placements or new business ventures. The explanation for this part of the case builds on a combination of mechanisms of attribution of threats and certification. Attribution of threats (McAdam et al. 2001) is a mechanism that accounts for the mobilization of actors once they come to share the framing of a situation as likely to bring about a loss and an understanding of possible actions (or inactions) in order to attain likely future outcomes. The case provides some evidence that the temporary employees shared an understanding of their job as subjected to the threat that their employment contracts could not be renewed depending on the availability of EU funding. A mechanism of certification (McAdam et al. 2001), which relates to the search for a validation of roles, performance, and claims by external authorities, may help account for the efforts of the temporary employees to seek to establish the legitimacy of their identities and role through the number of client cases that they serviced. In other words, temporary employees were not sure that their jobs would continue in the future. As a way of demonstrating the validity of their identities and roles within the CSL, and taking into account the newness of ALMP services, they focused their efforts on increasing the volume of their activity, because this result provided visible evidence that ALMP services were favorably received among the unemployed. Taking into account political context conditions that included a threat to the very existence of CSL, this mechanism may also help explain why CSL managers let the temporary staff primarily focus on increasing the number of client cases rather than service quality and effectiveness. Evidence of increased volume of activity in the delivery of ALMP services, in fact, could strengthen the persuasiveness of the claims about the benefits of the existing decentralized arrangement of public employment services.

The key components of the explanatory argument presented in this section are summarized in Table 2. Analytically relevant conditions include features of the permanent employees (an initial condition), the conflictual relationship between the regional government and the provincial governments and the sources of uncertainty about temporary employees' job prospects (context conditions), the enlargement of the statutory tasks of the public employment agencies and the allocation of competences on labor market policies between the 
region and the provinces (policy design features). In addition, we need to consider the causal role played by policy process features, such as the modality of employment of the temporary staff (that relates to conditions originating from the public sector financial domain), the periodical review meetings of CLS managers, and the 'silos' organizational design of the CSL (that relate to managerial interventions into the organizational change process). These conditions and policy process features help explain, together with hypothesized mechanisms, the development of work practices for the provisions of ALMP services. In sum, the protection of identities and roles induced the temporary staff to actively engage in learning how to design and implement routines for providing ALMP services; the perceived threat that temporary staff's jobs could terminate induced them to seek the certification of their activity especially by increasing the volume of client cases, rather than improving the service quality and effectiveness of ALMP services; the polarization between the permanent employees and the temporary staff did not result in detrimental conflicts anyway, for reasons especially related to the 'silos' organizational design. Managers of CSL may be credited with the design of interventions (including monthly review meetings) that facilitated the organizational change process. Their lack of efforts to improve the effectiveness of ALMP services, instead, may be partially understood in relation to adverse context conditions, in the form of uncertainties about the very existence of the CSL in the future, that induced them to share temporary staff's concern with providing visible evidence of positive reception of ALMP services among the unemployed.

$<$ insert Table 2 about here $>$

\section{CONCLUSIONS}

The central point of the explanatory argument made in this case study is that the path and outcome of the organizational change process in public employment agencies can be explained, in part, by the combination of various features of the institutional and temporal context and, in part, by helpful managerial interventions. Within the case, some context features seemed to work against the development of novel work practices, but temporary staff's inclination to assert their professional identities and roles and CLS managers' interventions resulted to effectively sustain the organizational change process over time.

This explanatory argument suggests some ways to reconsider the role played by 
political context conditions in the organizational change process in the public sector. By political context conditions we especially refer, within the present case study, to the conflictual relationship between government layers over the allocation of competences on labor market policies. Such political context conditions gave rise to uncertainties about the continuity of funding for the jobs of the temporary staff and about the very existence of CSL in the future. As already highlighted by scholarly works (Fernandez and Rainey 2006; May and Winter 2007), conditions that originate from the political environment, especially in the form of external support from political overseers and key external stakeholders and signals that affect employees' perceptions of policy goals and their knowledge, play an important role in the explanation of the organizational change process. In addition to this, the present case study helps to show how a conflictual relationship between government layers may cause organizational actors to sense a threat to their job stability and career prospects, that may affect decisions that are relevant for the development of novel work practices. As a particular feature of the present case study context, the concurrent presence of decentralization of labor market policies and enlargement of statutory tasks of public employment agencies allows the investigation of how political context conditions affect the path and outcome of the organizational change process, with respect to the existing literature on other countries' experience of implementing the 'activation turn' in labor market policy in Europe (Davister et al. 2004; Graziano 2012).

This explanatory argument also suggests some reflections upon the role of implementers in organizational change processes. Within the present case study, the willingness of temporary employees to implement change played an important role in the development of novel organizational practices. It seems that at least two features of the case are important to qualify the causal role played by this factor. First, temporary employees operated within a political context where the development of ALMP services could have important implications on their job stability and prospects. In other words, their willingness to implement change may be partially related to a 'natural inclination' to attain the best interest of clients and stakeholders, but also to the quest to legitimize their status as 'ALMP professionals' in face of hostile environmental circumstances. Second, temporary employees developed novel organizational practices in a context where the 'silos' design kept their activity largely insulated from permanent employees. This organizational arrangement may have helped to preserve temporary staff's willingness to implement change despite the 
skepticism towards ALMP services that was expressed by permanent employees. On the whole, these features of the case suggest that stewardship theory may help explain implementers' efforts to change organizational structure and practices, but also context conditions and managerial interventions should be taken into account in order to better understand the rationales for organizational actors' motivations to implement change and the organizational conditions that facilitate change to take place.

Finally, this study bears some limitations, which should be duly acknowledged. For reasons related to the explorative feature of this case study we should be cautious about drawing generalized arguments from the findings. In part, this concern may be addressed by remarking that the contribution of this case study is framed in the form of amendments and qualifications to existing theoretical arguments about the role of political context conditions and of implementers' 'natural inclination' to attain the best interests of clients and stakeholders. In this sense, the research contribution of this study is to offer 'limited generalizations' (Ragin 1987) about classes of social phenomena rather than 'covering laws' (Hedström 2005). In part, however, this concern may be also addressed by undertaking further research of a comparative kind, where the present case may be contrasted and compared to others where obstacles to organizational change are effectively overcome. 


\section{REFERENCES}

Argyris, C. and D. A. Schön (1996) Organizational Learning: A Theory of Action Perspective, Reading, MA: Addison-Wesley.

Armenakis, A. A. and A. G. Bedeian (1999) Organizational Change: A Review of Theory and Research in the 1990s. Journal of Management, 25(3): pp293-315.

Barzelay, M. and Gallego, R. (2006) From 'New Institutionalism' to 'Institutional Processualism': Advancing Knowledge about Public Management Policy Change. Governance, 19(4): pp531-557.

Beckerman, A. and L. Fontana (2001) The Transition from AFDC to PRWORA in Florida: Perceptions of the Role of Case Manager in Welfare Reform, Journal of Sociology \& Social Welfare, 28: pp29-47.

Brown, K., J. Waterhouse and C. Flynn (2003) Change Management Practices - Is A Hybrid Model A Better Alternative For Public Sector Agencies? International Journal of Public Sector Management 16(3): pp230-241.

Bryson, J. M. and S. R. Anderson (2000) Applying Large-Group Interaction Methods in the Planning and Implementation of Major Change Efforts. Public Administration Review, 60(2): pp143-162.

Butera \& Partners (2002) Un modello organizzativo per i nuovi Centri per l'Impiego, Rome: Butera \& Partners.

Calmfors, L. (1994) Active Labour Market Policy and Unemployment - A Framework for the Analysis of Crucial Design Features. OECD Economic Studies No. 22 (Spring). Paris: OECD.

Clasen, J. and D. Clegg (2003) Unemployment Protection and Labour Market Reform in France and Great Britain in the 1990s: Solidarity Versus Activation? Journal of Social Policy, 32(3): pp361-381.

Coram, R. and B. Burnes (2001) Managing Organisational Change in the Public Sector Lessons From the Privatization of the Property Service Agency. International Journal of Public Sector Management 14(2): pp94-110.

Davis, J. H., F. D. Schoorman and L. Donaldson (1997) Towards a Stewardship Theory of Management. Academy of Management Review, 22(1): pp20-48.

Davister, C., J. Defourny and O. Gregoire (2004) Work Integration Social Enterprises in the European Union: An Overview of Existing Models. EMES Working Papers No. 04/04.

Dawson, P. (1994) Organizational change: A processual approach, London: Chapman.

Devos, G., M. Buelens and D. Bouckenooghe (2007) Contribution of Content, Context, and 
Process to Understanding Openness to Organizational Change: Two Experimental Simulation Studies. The Journal of Social Psychology, 147(6): pp607-630.

Donaldson, L. and J. J. Davis (1989) CEO governance and shareholder returns: Agency theory or stewardship theory. Paper presented at the Annual Meeting of the Academy of Management, Washington, DC.

Donaldson, L. and J. J. Davis (1991) Stewardship Theory or Agency Theory: CEO Governance and Shareholder Returns. Australian Journal of Management, 16(1): pp49-64.

Eisenhardt, K. M. and M. E. Graebner (2007) Theory Building from Cases: Opportunities and Challenges. Academy of Management Journal, 50(1): pp25-32.

EU Commission (1998) Communication COM (1998) 641, Brussels: EU Commission.

Fernandez, S. and H. G. Rainey (2006) Managing Successful Organizational Change in the Public Sector. Public Administration Review 66: pp168-176.

Fiol, C. M. and M. A. Lyles (1985) Organizational Learning. Academy of Management Review 10 (4): pp803-13.

Gambetta, D. (1998) 'Concatenations of Mechanisms' in P. Hedström and R. Swedberg (eds) Social Mechanisms: An Analytic Approach to Social Theory, 102-125. Cambridge, MA: Cambridge University Press.

Gaskell, G. and M. Bauer (2000) 'Towards Public Accountability: beyond Sampling, Reliability, and Validity' in G. Gaskell and M. Bauer (eds) Qualitative Research with Image, Text, and Sound: A Practical Handbook, 102-125. London: Sage. 336-350.

George, A. L. and A. Bennett (2005) Case Studies and Theory Development in the Social Sciences, Cambridge, MA: MIT Press.

Graziano, P. (2012) Converging Worlds of Activation? Activation Policies and Governance in Europe and the Role of the EU, International Journal of Sociology and Social Policy, 32(5/6): pp312-326.

Greenwood, R. and C. R: Hinings (1996) Understanding Radical Organizational Change: Bringing together the Old and the New Institutionalism. The Academy of Management Review 21(4): pp1022-1054.

Harrow, J. (2001) Capacity Building as a Public Management Goal: Myth, Magic or the Main Chance? Public Management Review, 3(2): pp209-230.

Hedström, P. (2005) Dissecting the Social: On the Principles of Analytical Sociology, Cambridge, UK: Cambridge University Press.

Hedström, P. and R. Swedberg (eds) (1998) Social Mechanisms: An Analytic Approach to Social Theory, Cambridge, MA: Cambridge University Press. 
Higgs, M. and D. Rowland (2005) All Changes Great and Small: Exploring Approaches to Change and Its Leadership. Journal of Change Management, 5(2): pp121-151.

Judson, A. S. (1991) Changing Behavior in Organizations: Minimizing Resistance to Change. Cambridge, MA: Basil Blackwell.

Kelman, S. (2005) Unleashing Change: A Study of Organizational Renewal in Government, Washington, DC: Brookings Institution Press.

Kickert, W. J. M (2010) Managing Emergent and Complex Change: The Case of Dutch Agencification. International Review of Administrative Sciences, 76(3): pp489-515.

Layard, R., S. Nickell and R. Jackman (1991) Unemployment: Macroeconomic Performance and the Labour Market, Oxford: Oxford University Press.

Levitt, B. and J. G. March (1988) Organizational Learning. Annual Review of Sociology, 14: pp319-340.

Lewin, K. (1951) Field Theory in Social Science, Hew York: Harper.

Lipsky, M. (1980) Street-level Bureaucracy. New York: Russell Sage Foundation.

Lundin, M. and P. Skedinger (2000) Decentralisation of active labour market policy: The case of Swedish local employment service committees. Working paper No. 6. Uppsala, Sweden: IFAU - Office of Labour Market Policy Evaluation.

Lurie, I. and N. M. Riccucci (2003) Changing the "culture" of welfare offices: From vision to the front lines. Administration \& Society, 34: pp653-677.

Mahler, J. (1997) Influences of Organizational Culture in Learning in Public Agencies. Journal of Public Administration Research and Theory, 7(4): pp519-40.

Mahoney, J. (2000) Path Dependence in Historical Sociology, Theory and Society, 29(4): pp507-548.

Martin, J. P. (2000) What Works among Active Labour Market Policies: Evidence from OECD Countries' Experiences. OECD Economic Studies No. 30 2000/I. Paris: OECD.

McAdam, D., S. G. Tarrow and C. Tilly (2001) Dynamics of Contention, Cambridge, UK: Cambridge University Press.

Meyers, M. K., B. Glaser and K. Mac Donald (1998) On the Front Lines of Welfare Delivery: Are Workers Implementing Policy Reforms? Journal of Policy Analysis and Management, 17: pp1-22.

Pettigrew, A. M. (1997) What Is a Processual Analysis? Scandinavian Journal of Management, 13: pp337-348. 
Pettigrew, A. M., R. W. Woodman and K. S. Cameron (2001) Studying Organizational Change and Development: Challenges for Future Research. The Academy of Management Journal, 44(4): pp697-713.

Pierson, P. (2000) Increasing Returns, Path Dependence, and the Study of Politics. The American Political Science Review, 94(2): pp251-267.

Pierson, P. (2004) Politics in Time. History, Institutions, and Social Analysis, Princeton, NJ: Princeton University Press.

Pruna, M. L. (2011) Mercato del Lavoro in Sardegna: Rapporto 2011, Cagliari, Italy: CUEC.

Ragin, C. C. (1987), The Comparative Method. Berkeley, CA: University of California Press.

Riccucci, N. M., M. K. Meyers, I. Lurie and J. S. Han (2004) The Implementation of Welfare Reform Policy: The Role of Public Managers in Front-line Practices', Public Administration Review, 64: pp438-48.

Schelling, T. C. (1998) 'Social Mechanisms and Social Dynamics' in P. Hedström and R. Swedberg (eds) Social Mechanisms: An Analytic Approach to Social Theory, 32-44. Cambridge, MA: Cambridge University Press.

Singh, J. V., D. J. Tucker and R. J. House (1986) Organizational Legitimacy and the Liability of Newness. Administrative Science Quarterly 31: pp171-193.

Thaden, E. and J. Robinson (2010) Staff Narratives: Promising to Change 'Welfare as We Know It'. Qualitative Social Work, 11(1): pp23-41.

Thomas, C. W. (1993) Reorganizing Public Organizations: Alternatives, Objectives, and Evidence. Journal of Public Administration Research and Theory, 3(4): pp457-486.

Tummers, L. (2011) Explaining the Willingness of Public Professionals to Implement New Policies: A Policy Alienation Framework. International Review of Administrative Sciences, 77(3): pp555-581.

Tummers, L. and N. Karsten (2012) Reflecting on the Role of Literature in Qualitative Public Administration Review: Learning from Grounded Theory. Administration \& Society, 44(1): pp64-86.

Wallace, M., D. O'Reilly, J. Morris and R. Deem (2011) Public Service Leaders as 'Change Agents' - for Whom? Public Management Review, 13(1): pp65-93.

Weick, K. E. (2000) 'Emergent Change as a Universal in Organizations' in M. Beer and N. Nohria (eds) Breaking the Code of Change, 223-242. Cambridge, MA: Harvard University Press.

Wenger, E. (2007) Communities of Practice: Learning, Meaning, and Identity, Cambridge, 
MA: Cambridge University Press.

Wise, L. R. (2002) Public Management Reform: Competing Drivers of Change. Public Administration Review 62(5): pp555-567. 


\section{Tables}

\begin{tabular}{ll} 
Government layer & Total number of territorial entities \\
\hline Regions (Regioni) & 20 \\
Provinces (Province) & $110(107$ until 2004) \\
Municipalities (Comuni) & 8,092
\end{tabular}

Table 1. Italy's multi-layered system of governance

\section{Components of the explanatory argument}

\begin{tabular}{ll}
\hline Explanandum & Development of novel work practices for delivering ALMP services \\
\hline Initial conditions & Features of permanent employees \\
\hline Context conditions & Conflictual relationship between the region and provinces \\
\hline Policy design features & Enlargement of statutory tasks \\
& Allocation of competences to regions and provinces \\
\hline Policy process features & Modality of employment of the temporary staff \\
& Monthly review meetings \\
'Silos' organizational arrangement
\end{tabular}

Organizational learning

(Levitt and March, 1988; Argyris and Schön 1996)

Protection of identities and roles

(Wenger, 2007)

$\begin{array}{ll}\text { Hypothesized social mechanisms } & \begin{array}{l}\text { Polarization } \\ \text { (McAdam et al., 2001) }\end{array} \\ & \begin{array}{l}\text { Attribution of threats } \\ \text { (McAdam et al., 2001) }\end{array} \\ & \begin{array}{l}\text { Certification } \\ \text { (McAdam et al., 2001) }\end{array}\end{array}$
Organizational change process features

(1) 